\title{
Muc2 mucin limits Listeria monocytogenes dissemination and modulates its
}

$5 \quad{ }^{1}$ Division of Infectious Diseases, Brigham and Women's Hospital, Boston, Massachusetts, USA

$6 \quad{ }^{2}$ Department of Microbiology, Harvard Medical School, Boston, Massachusetts, USA

$7 \quad{ }^{3}$ Department of Immunology and Infectious Diseases, Harvard T.H. Chan School of Public Health,

8 Boston, Massachusetts, USA

$9 \quad{ }^{4}$ Howard Hughes Medical Institute, Boston, MA, USA

$10{ }^{5}$ current address, Department of Pharmacology, Keio University School of Medicine, Shinjuku-ku, Tokyo, Japan.

12 Running title: Muc2 modulates Listeria population dynamics

13

14 Corresponding author Matthew K. Waldor. Email: mwaldor@research.bwh.harvard.edu 


\section{Abstract}

The mucin Muc2 is a major constituent of the mucus layer that covers the intestinal epithelium and creates a barrier between epithelial cells and luminal commensal or pathogenic microorganisms. The Grampositive food-borne pathogen Listeria monocytogenes can cause enteritis and also disseminate from the intestine to give rise to systemic disease. L. monocytogenes can bind to intestinal Muc2, but the influence of the Muc2 mucin barrier on L. monocytogenes intestinal colonization and systemic dissemination has not been explored. Here, we used an orogastric L. monocytogenes infection model to investigate the role of Muc2 in host defense against L. monocytogenes. Compared to wild-type mice, we found that Muc2-mice exhibited heightened susceptibility to orogastric challenge with L. monocytogenes, with higher mortality, elevated colonic pathology, and increased pathogen burdens in both the intestinal tract and distal organs. In contrast, L. monocytogenes burdens were equivalent in wild-type and Muc2/-- animals when the pathogen was administered intraperitoneally, suggesting that systemic immune defects do not explain the heightened pathogen dissemination observed with oral infection route. Using a barcoded $L$. monocytogenes library to measure intra-host pathogen population dynamics, we found that Muc2/animals had larger pathogen founding population sizes in the intestine and distal sites than observed in wild-type animals. Comparisons of barcode frequencies revealed that, in the absence of Muc2, the colon becomes the major source for seeding the internal organs. Together, our findings reveal that Muc2 limits L. monocytogenes dissemination from the intestinal tract and modulates its population dynamics during infection. 


\section{Introduction}

Muc2 is a highly abundant O-glycosylated mucin glycoprotein that is primarily found on the

mucosal surface of the intestinal tract and forms a gel-like structure that is the principal component of the

by goblet cells, where it is oligomerized during intracellular trafficking and stored in secretory granules

prior to its secretion (3). Although distributed throughout the intestinal tract, the density and structural

51 organization of Muc2 within the mucus layer varies between sites; for example, two thick layers of Muc2

52 (a 'loose' outer layer and a 'firm' inner layer) are found in the colon, while only a porous mucus layer is

53 found in the small intestine $(1,4)$.

A major physiological role of Muc2 is the creation of a physical barrier that segregates the gut microbiota from the intestinal epithelium (5). This barrier function is augmented by the wire mesh-like structure of Muc2 that serves as a scaffold for binding and displaying host-derived antimicrobial peptides and microbial binding proteins (e.g. human $\beta$-defensins, Relm- $\beta$, and $\mathrm{Zg} 16$ ) (6-8). The extensive Oglycosylation of Muc2 exerts both microbe- and host-directed effects that support intestinal homeostasis, by supplying nutrients (e.g. carbohydrate moieties) to promote the expansion of gut commensal species,

61 Muc2 production and secretion by goblet cells is also integrated into intestinal defense systems against enteric pathogens. For instance, Birchenough et al. found that a subpopulation of goblet cells in the colon release Muc2-containing granules in response to direct sensing of pathogen associated molecular patterns

64 via the intrinsic Nlrp6 (NOD-like receptor family pyrin domain-containing 6)-dependent inflammasome

65 (11). In addition, goblet cells undergo hyperplasia and increase their mucus granule sizes in response to signals generated by other intestinal sentinel cells (e.g. Tuft cells) during infection (12). 
The impacts of Muc2 on gut homeostasis and host defense against enteric pathogens have been revealed by studies of mice harboring a targeted knockout of the Muc2 gene (Muc2 ${ }^{-/}$) (13). These Muc2/- animals exhibit a reduced gap between luminal commensal bacteria and the intestinal epithelium $(5,14)$, epithelial hyperplasia $(13,14)$, increased colonic immune cell infiltration (15), altered microbiota (16),

71 and elevated frequencies of colon cancer (13). Similar phenotypes have also been observed in a mouse 72 strain (the "Winnie mouse") with a missense mutation in the Muc2 gene $(17,18)$. Besides intestinal tract 73 anomalies, Muc2 ${ }^{-/-}$mice have systemic inflammation, higher titers of antibodies against bacterial 74 lipopolysaccharide (LPS) and flagellin, and elevated levels of iron in circulation (19). In addition, Muc2$75^{1-}$ mice have been found to be more susceptible to challenges with enteric pathogens, including Citrobacter rodentium, Salmonella typhimurium, the nematode parasite Trichuris muris, and the protozoal parasite

77 Entamoeba histolytica $(14,20-22)$.

L. monocytogenes is a Gram-positive foodborne bacterial pathogen that can cause enteritis as well as additional disease manifestations, such as meningitis, that result from its systemic dissemination from the intestinal tract (23). Observations from a rat ligated ileal loop model revealed that L. monocytogenes

81 forms aggregates on intestinal mucus and induces goblet cell degranulation (24). Several $L$. monocytogenes surface proteins have been reported to bind to Muc2 (25), potentially mediating the

83 pathogen's attachment to mucus. Using the mucin-expressing cell line HT29X, Coconnier et al. found 84 that listeriolysin $\mathrm{O}$ (LLO) is the major bacterial component that triggers mucin exocytosis $(26,27)$. 85 Although goblet cell degranulation is generally recognized as a host defense strategy, L. monocytogenes 86 is thought to target these mucin-secreting cells to gain access to its host receptor in the intestine, E87 cadherin (28). Here, we used Muc2-/- mice and an orogastric L. monocytogenes infection model to investigate the 
(WT) mice, Muc2-deficient animals had heightened susceptibility to orogastric challenge with $L$.

91

92

93

monocytogenes, exhibiting elevated mortality, more severe colonic pathology and increased bacterial burden in the intestine and distal organs. In contrast, pathogen burdens were similar in Muc2 ${ }^{+/+}$and Muc2/- animals after intraperitoneal inoculation of L. monocytogenes. By using barcoded L. monocytogenes (29), we investigated the impact of Muc2 mucin on L. monocytogenes population dynamics during infection. Muc2 ${ }^{-/-}$animals had larger pathogen founding population sizes at intestinal and distal sites and the genetic relatedness between these bacterial populations exceeded that in WT mice. Together, these findings suggest that Muc2 guards against L. monocytogenes dissemination from the intestine and demonstrate that this mucin modulates pathogen population dynamics during infection.

\section{Results}

\section{Muc2 $^{-/-}$mice have heightened susceptibility to orogastric challenge with $L$. monocytogenes}

To assess the role of Muc2 in host defense against L. monocytogenes, littermate offspring of $\mathrm{Muc}^{+/-}$breeders were orogastrically challenged with L. monocytogenes $10403 \mathrm{~S}$ InlA , a 'murinized' variant of a human clinical isolate that contains a InlA allele with enhanced binding to murine E-cadherin (30). Remarkably, 92\% (11 out of 12) of Muc2 $2^{-/-}$mice died during the 8 -day observation period post pathogen challenge (Fig 1a), whereas only 17\% (2 out of 12) of WT (Muc2 ${ }^{+/+}$) mice succumbed (Fig 1a). In addition, Muc2 $2^{-/-}$mice began to die earlier than WT mice (Fig 1a) and lost more weight (Fig 1b). Several of the Muc2 $2^{--}$mice developed diarrhea $\sim 3$ days post inoculation (DPI) (Fig S1); in contrast, WT mice do not develop diarrhea in this model. Together these observations indicate that Muc2 provides protection from the morbidity and mortality of L. monocytogenes infection in mice.

\section{L. monocytogenes infection exacerbates colonic inflammation in $\mathrm{Muc2}^{-/-}$mice}


The absence of Muc2 is thought to largely eliminate the physical barrier between luminal commensal bacteria and the colonic epithelium, triggering microbially-induced intestinal inflammation (15). Colons from L. monocytogenes-infected Muc2-/- mice were visibly more swollen than colons from 116 infected WT mice, suggestive of exacerbated intestinal inflammation in the Muc2 $2^{-/}$group (Fig 2a, b). 117 Furthermore, the masses of the distal colons from both uninfected and infected Muc $2^{-/-}$mice were greater 118 than those from corresponding WT mice (Fig 2c); such differences were not observed in the proximal 119 colons from either uninfected or infected animals (Fig S2). The elevated mass of the distal colon in Muc2$120{ }^{/}$- mice is likely attributable to the influx of immune cells and proliferation of local colonic epithelial cells 121 (14), but the factors that restrict these processes to the distal colon are not clear. Muc2 $^{-/-}$mice were significantly shorter than those from WT mice at 3 DPI (Fig 2a, d). In contrast, colon 124 lengths were similar in uninfected Muc2 $2^{-/-}$and WT animals (Fig 2a, d), suggesting that lack of Muc2 125 mucin by itself is not sufficient to provoke longitudinal colon shrinkage. As L. monocytogenes challenge 126 did not alter colon length in WT mice (Fig 2d), these observations suggest that infection-induced colon 127 shortening in Muc2 $2^{-/-}$mice is due to the combined effects of the Muc2 mucin deficit and the presence of 128 the pathogen. our visual observations of gross pathology. Notably, in Muc2 $2^{-/-}$mice, infection induced massive immune

131 cell infiltration into the colonic lamina propria, heightened erosion of colonic epithelial cells, and 132 increased granulocytes in the colon lumen (Fig 2e). In marked contrast, there was no detectable immune cell infiltration within the colonic lamina propria of WT mice (Fig 2e). Overall, with the exception of 134 granulocytes in the lumen of the distal colon in a subset of the WT mice, there was limited pathology 
observed in colons from WT mice 3DPI (Fig 2e). Thus, the absence of Muc2 elevates the intestinal inflammatory response to L. monocytogenes.

\section{Muc2 mucin modulates $L$. monocytogenes intestinal colonization and dissemination}

To address the impact of Muc2 on bacterial colonization, bacterial burdens in the intestines of markedly augments the accessibility of intracellular niches to the pathogen at this site. dissemination from the gut to distal sites. Furthermore, a higher percentage of Muc $2^{-/-}$mice carried $L$.

(Fig 3g). Our unpublished observations suggest that there is a positive correlation between hepatic $L$. colonization in the Muc2-deficient animals is a consequence of the higher pathogen burden in their livers.

155 Even though the Muc2-deficient animals were more likely to have GB colonization than WT mice, the 
Kumar et al. recently reported that $\mathrm{Muc}^{-/-}$mice have an elevated basal level of systemic inflammation (19), suggesting that the absence of a Muc2 barrier alters physiology in distal organs. To test whether $\mathrm{Muc}^{-/-}$mice have deficiencies in controlling systemic L. monocytogenes infection, WT and Muc2 $^{-/-}$mice were challenged with $10^{5} \mathrm{CFU}$ of L. monocytogenes via the intraperitoneal (i.p.) route. In contrast to our observations with oral inoculation (Fig 3), similar numbers of L. monocytogenes were recovered from the MLN, spleen, and liver in WT and Muc2 $2^{-/}$mice 3 days following i.p. inoculation (Fig the infection. In addition, Muc2 $2^{-/}$and WT mice exhibited similar weight loss and had comparable colon lengths post i.p. challenge (Fig 4d-e), suggesting that the susceptibility of Muc2-/ mice to oral pathogen challenge is not explained by a systemic immune defect.

\section{Muc2 mucin alters L. monocytogenes population dynamics}

Since we found that the Muc2-containing intestinal mucus barrier modulates L. monocytogenes

171 intestinal colonization and dissemination, we leveraged Sequence Tag-based Analysis of Microbial 172 Populations (STAMP) $(29,32)$ to investigate the impact of Muc2 on L. monocytogenes population 173 dynamics during infection. In this method, DNA-barcoded, but otherwise WT, L. monocytogenes are used 174 to calculate the number of bacteria from the inoculum that seed various infection sites (the founding 175 population, $(\mathrm{Nb}))(29)$. Notably, in orally infected mice, $N \mathrm{~b}$ values from intracellular (gentamicin-treated) 176 proximal and distal colon samples were significantly higher in Muc2 ${ }^{-/-}$vs WT animals (Fig 5a, b). The 177 difference was particularly pronounced in the distal colon where $\mathrm{Nb}$ was $\sim 2000$ in Muc2 $2^{-/-}$vs $\sim 50$ in WT 178 mice (Fig 5b), suggesting that Muc2 provides an especially stringent barrier for the pathogen at this site.

179 Presumably, the absence of the Muc2 mucin facilitates pathogen access to permissive niches within 180 colonic epithelial cells. In addition, the increased influx of immune cells and their accumulation in the 
181 colonic lamina propria of $\mathrm{Muc} 2^{-/-}$mice (Fig 2e) may provide additional niches for L. monocytogenes 182 growth, since the pathogen is known to replicate in these cells (33).

$\mathrm{Nb}$ sizes in internal organs also differed between $\mathrm{Muc}^{-/-}$and WT animals. $\mathrm{bb}$ values in MLNs, spleens, and livers of Muc2 $2^{-/-}$mice were higher than in WT mice, but only reached statistical significance in MLNs (Fig. 5c-e). These observations are consistent with the idea that the Muc2 mucin barrier imposes a bottleneck on L. monocytogenes dissemination from the intestine. In contrast, even though $100 \%$ of 187 Muc2 $^{-/-}$mice harbored L. monocytogenes in their GBs, Nb sizes in GBs from Muc2 ${ }^{-/-}$were similarly extremely low (mean $\mathrm{Nb}=3$, Fig. S3) as observed before (29), suggesting that Muc2 does not contribute to the host barrier that restricts L. monocytogenes access to the GB. the genetic relatedness between bacterial populations recovered from different sites (32). In WT mice, bacterial populations from the proximal (Fig 5f-h) or distal (Fig 5i-k) colon were relatively distinct from those resident in the MLN, spleen, and liver (i.e. small 'genetic relatedness' values). These low values are 194 similar to observations we made with Balb/c mice (29), which are more permissive to L. monocytogenes 195 infection than C57BL/6 mice, and indicate that L. monocytogenes disseminates from the intestinal tract to 196 distal organs using multiple independent routes $(29,34)$. In contrast, in Muc2 $2^{-/-}$mice, these comparisons 197 revealed a statistically significant higher degree of relatedness between bacterial populations recovered 198 from either the proximal (Fig 5f-h) or distal (Fig 5i-k) colon and those from the MLN, spleen, and liver 199 than found in WT animals. These observations suggest that the increases in absolute and founding $L$. 200 monocytogenes population sizes in the proximal and distal colon (Fig 3bc and 5ab) that are associated 201 with the absence of Muc2 mucin also enable the colon to become the major source for seeding the internal 202 organs. Collectively, these findings reveal that the absence of Muc2 mucin alters L. monocytogenes 203 population dynamics during infection. 


\section{Discussion}

Here, we found that Muc2 $2^{--}$mice have heightened susceptibility to orogastric challenge with $L$. monocytogenes. Compared to WT mice, animals lacking Muc2 exhibited elevated mortality, more severe colonic pathology and increased pathogen burdens in the intestine as well as in distal organs following oral inoculation of L. monocytogenes. The heightened sensitivity of Muc2 $2^{-/-}$mice appears to be dependent on the route of infection, since we found that L. monocytogenes burdens were equivalent in WT and Muc2deficient animals when the pathogen was administered intraperitoneally. Furthermore, our experiments with barcoded L. monocytogenes demonstrated that Muc2 restricts L. monocytogenes founding population sizes, particularly in the colon. In the absence of the Muc2 barrier, the colon becomes the dominant site

214 from which the pathogen disseminates to distal organs. Together these observations reveal that Muc2 mucin modulates L. monocytogenes colonization, dissemination and population dynamics. limits the access of commensal as well as pathogenic microorganisms to the epithelial surface of the 219 intestine $(5,35)$; a thinned/absent mucus layer that lacks Muc2 likely facilitates the pathogen's capacity to approach and ultimately invade intestinal epithelial cells. This host defense mechanism has been 221 postulated for other enteric pathogens including Citrobacter rodentium and Salmonella typhimurium, 222 where increased direct contact of these pathogens with the colonic epithelium of Muc2 $2^{-/-}$mice was 223 observed $(14,21)$. Second, increased mucus flow during enteric infection expels pathogens from the 224 epithelial surface and is thought to be a host defense mechanism (36). Consistent with this idea, 225 impairment of mucin exocytosis from goblet cells, e.g. by deletion of vesicle-associated membrane protein 
227 Entamoeba histolytica $(37,38)$. Although the function of goblet cell secretory granules in Muc2 ${ }^{-/-}$mice

228 has not been precisely described, a "flush out" strategy may be ineffective in Muc2 ${ }^{-/-}$mice given the 229 absence of Muc2. Altered mucus homeostasis could lead to goblet cell dysfunction, a phenotype that may 230 increase L. monocytogenes' access to its host receptor E-cadherin (39). Indirect consequences of the 231 absence of Muc2, including changes in the composition of the microbiota (16) and elevated basal colonic 232 inflammation (15), may also contribute to the susceptibility of Muc2 $2^{-/-}$mice to oral infection with $L$. 233 monocytogenes.

Besides Muc2's critical physical role in the structure and function of intestinal mucus, mucin glycans can serve as sources of nutrition for pathogens and are important regulators of bacterial pathogenicity (40-42). For example, O-glycans on MUC5AC can suppress the virulence of Pseudomonas aeruginosa, facilitating its clearance in a porcine burn wound model (41). The absence of such interkingdom regulatory signals in $\mathrm{Muc}^{-/-}$mice might modulate the L. monocytogenes virulence gene program and thus impact L. monocytogenes systemic dissemination.

Kumar et al. recently reported that $\mathrm{Muc}^{-/-}$mice have elevated basal levels of systemic 241 inflammation and circulatory iron, conditions that may promote growth of disseminated bacteria and were 242 associated with increased susceptibility to i.p. challenge with LPS (19). This suggested that animals with 243 whole body knockouts of Muc2 have systemic defects in their response to PAMPs. However, such changes 244 did not appear to alter the capacity of $\mathrm{Muc}^{-/-}$mice to control systemic infection caused by i.p. 245 administration of L. monocytogenes, as pathogen burdens were similar after this route of infection in WT 246 and Muc2 $2^{-/-}$mice. Further work will be required to decipher the potential extra-intestinal contributions of 247 Muc2 to host defense against pathogens, which may be challenge- and tissue-specific. 
containing mucus (1). We found that the effects of the absence of Muc2 were particularly marked in the

251 distal colon, where there was a drastic increase in the burden of intracellular L. monocytogenes; there was

only a moderate elevation in the pathogen burden in the ileum and proximal colon. Consistent with our observations, in a Muc2 $2^{-/}$mouse model of spontaneous colitis, the distal colon was found to have more neutrophilic infiltrates compared to the proximal colon (15). The distal colon is distinguished by a thick inner mucus layer that is not easily penetrated by microbes $(35,43,44)$, and a population of goblet cells that supports the rapid renewal of mucus within this inner layer (45). The severe phenotype we observed in the distal colon supports the idea that this region of the intestine is particularly reliant on Muc2producing goblet cells for defense.

Muc2 deficiency not only affects the pathogen burden in host tissues, but also alters the pathogen's population dynamics. Our previous (29) and present observations, in two different strains of mice, are consistent with the hypothesis that L. monocytogenes disseminates from the intestinal tract to distal organs using multiple independent routes, a pattern that has been referred to as "episodic spread" (29). Notably, 263 the pathogen's dissemination pattern was altered in the Muc2 ${ }^{-/-}$mice. The genetic relatedness of the $L$. monocytogenes populations recovered from the colon and distal organs (MLN, spleen, and liver) was 265 significantly higher than observed in WT mice, suggesting that the colon is the source for a larger fraction 266 of organisms that disseminate in Muc2 ${ }^{-/-}$versus WT mice. We also observed a marked increase in both 267 the L. monocytogenes burden and founding population size in the colon of Muc2/- mice. Together these 268 observations suggest that Muc2 in the colon is a critical host restriction factor that ordinarily prevents $L$. 269 monocytogenes colonization and invasion of epithelium. The absence of this physical host barrier enables 270 the colon to become the reservoir for dissemination. Heightened basal colonic inflammation in Muc $2^{-/-}$ 271 mice (15) also may contribute to L. monocytogenes proliferation and prolong infection. A deeper 272 understanding of the consequences of and mechanisms by which perturbations of intestinal structure and 
273 function modify host defense could provide insight to guide new treatment strategies for disorders where

274 intestinal insults promote systemic disease presentations, such as inflammatory bowel disease.

275

276

277

278

279 Figure legend

Figure 1. Muc2 $^{-/-}$mice have heightened susceptibility to orogastric challenge with L. monocytogenes.

281

282

(a) Survival curves of Muc2-/- mice $(n=12)$ and WT littermates $\left(\right.$ Muc2 $\left.^{+/+}, n=12\right)$ following orogastric challenge with $\sim 3 \times 10^{9} \mathrm{CFU}$ L. monocytogenes $10403 \mathrm{~S} \mathrm{InlA}^{\mathrm{m}}$. Mice were monitored every 12 hours for 8 days. The data are from two independent experiments; the Gehan-Breslow-Wilcoxon test was used to compare the survival curves $(* * * * \mathrm{p}<0.0001)$. (b) Weight of Muc2-/- $(\mathrm{n}=14)$ and WT $(\mathrm{n}=15)$ mice during the first 3 days post orogastric inoculation of L. monocytogenes. Data are from three independent experiments; Two-way ANOVA and Bonferroni's multiple comparison test were used to assess significance $(* * \mathrm{p}<0.01$ and $* * * * \mathrm{p}<0.0001)$

\section{Figure 2. L. monocytogenes infection exacerbates colonic inflammation in Muc2 ${ }^{-/}$mice.}

(a) Representative images of colons from uninfected ( $\mathrm{Lm} \mathrm{-}$ ) and infected $(\mathrm{Lm}+)$ Muc2 $2^{-/-}$and WT mice at 3 days post inoculation (DPI). (b) Expanded images of distal colons shown in (a). (c-d) Weight of the distal colon (c) and length of entire colon (d) in uninfected and infected Muc2 ${ }^{-/-}$and WT mice at 3 DPI; 9 to 13 mice per group in (c) and 8 to 9 mice per group in (d). (e) Hematoxylin and eosin (H\&E)-stained distal colonic tissue from uninfected and infected Muc2 $2^{-/-}$and WT mice at $3 \mathrm{DPI}$; the yellow arrows show immune cell infiltration and the green arrow shows sites of epithelial cell erosion; the blue arrows show 
granulocytes in the lumen. ANOVA and Fisher multiple comparison test were used to assess significance

297 in c-d (n.s. not significant, $* * \mathrm{p}<0.01$ and $* * * * \mathrm{p}<0.0001)$.

Figure 3. Elevated L. monocytogenes intestinal colonization and dissemination in Muc2 ${ }^{-/-}$mice.

Burden of L. monocytogenes in the ileum (a), proximal colon (b), distal colon (c), MLN (d), spleen (e),

301 liver (f), and gallbladder (g) at 3 DPI in orogastrically infected Muc $2^{-/-}$and WT mice. The intestinal samples (a-c) were treated with gentamicin to kill extracellular bacteria. Data are from three independent experiments with 10 to 15 mice per group. The Mann-Whitney test were used to assess significance $(* *$ $\mathrm{p}<0.01, * * * \mathrm{p}<0.001, * * * * \mathrm{p}<0.0001)$

Figure 4. Muc2 $^{-/-}$and WT littermate mice have similar pathogen burdens and disease manifestations post intraperitoneal challenge with $L$. monocytogenes.

Muc2 $^{-/-}(\mathrm{n}=8)$ and WT $(\mathrm{n}=8)$ mice were challenged with $1 \times 10^{5}$ CFU of L. monocytogenes $10403 \mathrm{~S}$ InlA ${ }^{\mathrm{m}}$ via the intraperitoneal route. Pathogen burdens recovered from MLN (a), spleen (b), and liver (c) at 3 DPI. (d) Weight of $\mathrm{Muc}^{-/-}$and WT mice for three days following i.p. inoculation.

(e) Colon lengths were measured at 3 DPI.

Figure 5. L. monocytogenes population dynamics differ in $\mathrm{Muc2}^{-/-}$and WT mice.

314 Founding population size $(\mathrm{Nb})$ of L. monocytogenes recovered from proximal colon (a) and distal colon 315 (b) of $\mathrm{Muc}^{-/-}(\mathrm{n}=11)$ and WT $(\mathrm{n}=13)$ mice at $3 \mathrm{DPI}$; data are from three independent experiments. $N \mathrm{~b}$ 316 of L. monocytogenes recovered from MLN (c), spleen (d), and liver (e) of Muc2 ${ }^{-/-}(\mathrm{n}=6)$ and WT $(\mathrm{n}=4)$ 317 mice at 3 DPI. (f-k) Genetic relatedness of L. monocytogenes recovered from different sites of Muc $2^{-/-}(\mathrm{n}$ 
$318=6)$ and WT $(\mathrm{n}=4)$ mice 3 DPI. Mann-Whitney tests were used to assess significance in a-k $(*=\mathrm{p}<0.05$, $319 * * \mathrm{p}<0.01$, and $* * * * \mathrm{p}<0.0001)$

Figure S1. Muc2 $^{-/-}$but not WT mice develop diarrhea after orogastric challenge with $L$.

monocytogenes.

$323 \mathrm{Muc}^{-/-}$mice and WT were challenged via orogastric route with $\sim 3 \times 10^{9} \mathrm{CFU}$ of L. monocytogenes

324 10403S InlA ${ }^{\mathrm{m}}$. Muc2 $2^{-/-}$mice (right) but not WT mice (left) developed diarrhea-like symptoms at 3DPI.

Figure S2. The weight of the proximal colon was not changed by $L$. monocytogenes infection in

327 Muc2 $^{-/-}$mice.

328 Weight of the proximal colon of uninfected and infected Muc2 ${ }^{-/-}$and WT mice at 3 DPI; 9-13 mice/group.

329 ANOVA and Fisher multiple comparison test were used to assess significance (n.s. not significant).

Figure S3. Gallbladder $\mathrm{Nb}$ values in orogastrically infected $\mathrm{Muc2}^{-/-}$mice

L. monocytogenes populations that were recovered from bile of Muc2 $2^{-/}$mice at 3 DPI were used for determination of $N \mathrm{~b}$ values; data $(\mathrm{n}=10)$ are from three independent experiments.

\section{Methods}

336 Bacterial strains and culture conditions. The Listeria monocytogenes strain used in this study (Lm337 STAMP-200 library, Supplementary table 1) is a barcoded derivative (29) of L. monocytogenes 10403S $338 \operatorname{InlA}^{\mathrm{m}}$, a strain where internalin A contains two amino acid substitutions that increase its capacity to bind 339 murine E-cadherin (30). For animal studies, aliquots of Lm-STAMP-200 library were cultured in brain 340 heart infusion (BHI; BD Biosciences) broth with chloramphenicol $(\mathrm{Cm}, 7.5 \mu \mathrm{g} / \mathrm{mL})$ and streptomycin $(\mathrm{Sm}$, 
$341200 \mu \mathrm{g} / \mathrm{mL})$ at $37^{\circ} \mathrm{C}$ for 3 hours. Bacteria were pelleted by centrifugation $(3,000 \times \mathrm{g}$ for 10 min $)$, washed

342 twice with $20 \mathrm{ml}$ phosphate-buffered saline (PBS) and diluted to the indicated concentration in PBS for

343 inoculation.

Animal studies. C57BL/6 Muc2 $2^{-/-}$mice used in this study were a gift from Dr. Anna Velcich (13) and were bred at the Harvard Institutes of Medicine animal facility. Mice were genotyped at 3-week-old and

$347 \mathrm{Muc2}^{+/+}(\mathrm{WT})$ and Muc2 ${ }^{-/-}$mice were cohoused until 10 to 12-week-old. Gender- and age-matched 348 littermates that were the offspring of heterozygous Muc $2^{+/}$breeders were used throughout the study. As 349 observed by other groups (46), a small fraction of Muc2 $2^{-/-}$animals $(\sim 10 \%)$ in our colony developed 350 spontaneous colon prolapse by 10-12 weeks of age; these mice were euthanized and excluded from the 351 study. For orogastric infection studies, WT and Muc2 $2^{-/-}$littermates were fasted for 8 hours prior to 352 infection and orally inoculated with $\sim 3 \times 10^{9}$ CFUs of barcoded L. monocytogenes (200 $\left.\mu \mathrm{L}\right)$ suspended 353 in a $300 \mu \mathrm{L}$ mixture of $200 \mathrm{mM} \mathrm{CaCO}_{3}$. For intraperitoneal infection studies, WT and Muc2 $2^{-/-}$littermates 354 were administered $\sim 1 \times 10^{5}$ CFU of barcoded L. monocytogenes $(200 \mu \mathrm{L})$ in PBS via i.p. injection. Mouse 355 bodyweights were measured prior to inoculation and daily post-inoculation for 3 days. To assess gross 356 intestinal pathology, animals were euthanized 3 DPI and the length and weight of colons were measured. 357 For survival curve analysis after orogastric inoculation, animals were monitored twice per day for 8 days.

359 To assess bacterial burden, animals were euthanized 3 DPI and organs [ileum (distal one-third of SI), 360 colon, MLN, spleen, liver, and GB] were collected. Colonic tissues were equally divided into two parts 361 and designated as proximal colon and distal colon. Proximal colons, distal colons, and ileums were cut 362 open longitudinally, incubated in DMEM with $100 \mu \mathrm{g} / \mathrm{mL}$ gentamicin for $2 \mathrm{~h}$ to kill the extracellular 363 bacteria, transferred to $50 \mathrm{ml}$ conical centrifuge tubes (Corning), washed with $25 \mathrm{~mL}$ of PBS five times 
on a rotator. The intestinal segments, MLN, spleen, and liver were homogenized in sterile PBS using a beat-beater (BioSpec Products); To collect bile, GBs were transferred to Eppendorf tubes containing $1 \mathrm{~mL}$ of PBS and ruptured with a 23-gauge needles (Becton Dickinson). For CFU enumeration, all of the homogenates/samples were serially diluted, plated on BHI-Sm plates, and kept at $37{ }^{\circ} \mathrm{C}$ for $48 \mathrm{~h}$. For STAMP analysis, homogenates/samples were directly plated on $245 \mathrm{~mm} \times 245 \mathrm{~mm}$ square BHI-Sm plates (Corning).

Histological analysis. Distal colons from WT and $\mathrm{Muc}^{-/-}$animals 3 DPI were fixed in 4\% paraformaldehyde (PFA) for $2 \mathrm{~h}$, transferred to $70 \%$ ethanol and kept at $4{ }^{\circ} \mathrm{C}$ overnight. Samples were embedded in Tissue-Tek OCT solution (Sakura Finetek) and sliced into $10 \mu \mathrm{M}$ sections using a Leica

374 CM1860 UV cryostat. Samples were stained with hematoxylin and eosin, mounted with 375 Organo/Limonene mounting medium (Sigma) and scanned (200 × magnification) using a Nikon confocal microscope.

STAMP protocol. Calculation of $\mathrm{N}_{\mathrm{b}}$ and genetic relatedness was performed as previously described (29, 32). Briefly, L. monocytogenes colonies from the indicated organs were washed off of the BHI-Sm plates with PBS. Cells were pelleted and genomic DNA was extracted (Wizard Genomic DNA Purification Kit;

Promega) from $\sim 1 \times 10^{10}$ bacteria. The region that harbors the 30 -bp barcodes was amplified from genomic DNA using primer PLM30 and primer PLM6-P29 (Supplementary table 1). The PCR products were purified (MinElute; Qiagen) and quantified (Qubit dsDNA HS Assay Kit; Life Technologies).

Purified PCR products were combined in equimolar concentrations and sequenced on an Illumina MiSeq

385 (Miseq Reagent Kit V2, 50-cycle; Illumina) using primer PLM49. Reaper-12-340 was used to discard sequence reads with low quality $(\leq \mathrm{Q} 30)$ and to trim the sequence following the barcode $(47)$. The trimmed 
sequences were clustered with QIIME (version 1.6.0) using pick_otus.py with a sequence similarity threshold of 0.9 (48). $\mathrm{N}_{\mathrm{b}}$ was then calculated using a custom R script. Genetic distance was estimated using the Cavalli-Sforza chord distance method (49) as described by Abel et al (32). Genetic relatedness is 1 - genetic distance.

Ethics statement. Animal experiments in this study were carried out in accordance with the NIH Guide for Use and Care of Laboratory animals and were approved by the Brigham and Women's Hospital IACUC (2016N000416). Mice were euthanized by isoflurane inhalation followed by cervical dislocation.

\section{Acknowledgments.}

We thank Dr. Anna Velcich for providing Muc2 ${ }^{-/}$mice. We thank members of the Waldor laboratory for helpful discussions. T.Z. was supported by a Sarah Elizabeth O'Brien Trust Postdoctoral Fellowship. This work was supported by NIH Grant RO1-AI-042347 (to M.K.W.), and the Howard Hughes Medical Institute (M.K.W.).

\section{References}

1. Johansson MEV, Larsson JMH, Hansson GC. 2011. The two mucus layers of colon are organized by the MUC2 mucin, whereas the outer layer is a legislator of host-microbial interactions. Proc Natl Acad Sci USA 108 Suppl 1:4659-4665.

2. Axelsson MA, Asker N, Hansson GC. 1998. O-glycosylated MUC2 monomer and dimer from LS $174 \mathrm{~T}$ cells are water-soluble, whereas larger MUC2 species formed early during biosynthesis are insoluble and contain nonreducible intermolecular bonds. J Biol Chem 273:18864-18870.

3. Ambort D, Johansson MEV, Gustafsson JK, Nilsson HE, Ermund A, Johansson BR, Koeck PJB, Hebert H, Hansson GC. 2012. Calcium and pH-dependent packing and release of the gelforming MUC2 mucin. Proc Natl Acad Sci USA 109:5645-5650. 
411 4. Johansson MEV, Sjövall H, Hansson GC. 2013. The gastrointestinal mucus system in health and disease. Nat Rev Gastroenterol Hepatol 10:352-361.

5. Johansson MEV, Phillipson M, Petersson J, Velcich A, Holm L, Hansson GC. 2008. The inner of the two Muc2 mucin-dependent mucus layers in colon is devoid of bacteria. Proc Natl Acad Sci USA 105:15064-15069.

6. Antoni L, Nuding S, Weller D, Gersemann M, Ott G, Wehkamp J, Stange EF. 2013. Human

7. Propheter DC, Chara AL, Harris TA, Ruhn KA, Hooper LV. 2017. Resistin-like molecule $\beta$ is a bactericidal protein that promotes spatial segregation of the microbiota and the colonic epithelium. Proc Natl Acad Sci USA 114:11027-11033.

8. Bergström JH, Birchenough GMH, Katona G, Schroeder BO, Schütte A, Ermund A,

9. Shan M, Gentile M, Yeiser JR, Walland AC, Bornstein VU, Chen K, He B, Cassis L, Bigas Johansson MEV, Hansson GC. 2016. Gram-positive bacteria are held at a distance in the colon mucus by the lectin-like protein ZG16. Proc Natl Acad Sci USA 113:13833-13838.

10. Arike L, Hansson GC. 2016. The Densely O-Glycosylated MUC2 Mucin Protects the Intestine and Provides Food for the Commensal Bacteria. J Mol Biol 428:3221-3229.

11. Birchenough GMH, Nyström EEL, Johansson MEV, Hansson GC. 2016. A sentinel goblet cell guards the colonic crypt by triggering Nlrp6-dependent Muc2 secretion. Science 352:15351542.

12. Gerbe F, Sidot E, Smyth DJ, Ohmoto M, Matsumoto I, Dardalhon V, Cesses P, Garnier L, Pouzolles M, Brulin B, Bruschi M, Harcus Y, Zimmermann VS, Taylor N, Maizels RM, Jay P. 2016. Intestinal epithelial tuft cells initiate type 2 mucosal immunity to helminth parasites. Nature 529:226-230.

13. Velcich A, Yang W, Heyer J, Fragale A, Nicholas C, Viani S, Kucherlapati R, Lipkin M, Yang K, Augenlicht L. 2002. Colorectal cancer in mice genetically deficient in the mucin Muc2. Science 295: 1726-1729.

14. Bergstrom KSB, Kissoon-Singh V, Gibson DL, Ma C, Montero M, Sham HP, Ryz N, Huang T, Velcich A, Finlay BB, Chadee K, Vallance BA. 2010. Muc2 protects against lethal infectious colitis by disassociating pathogenic and commensal bacteria from the colonic mucosa. PLoS Pathog 6:e1000902.

15. Wenzel UA, Magnusson MK, Rydström A, Jonstrand C, Hengst J, Johansson MEV, Velcich A, Öhman L, Strid H, Sjövall H, Hansson GC, Wick MJ. 2014. Spontaneous colitis in Muc2deficient mice reflects clinical and cellular features of active ulcerative colitis. PLoS ONE 9:e100217. 
bioRxiv preprint doi: https://doi.org/10.1101/2020.10.21.348896; this version posted October 21, 2020. The copyright holder for this preprint

(which was not certified by peer review) is the author/funder, who has granted bioRxiv a license to display the preprint in perpetuity. It is made available under aCC-BY-NC-ND 4.0 International license.

16. Wu M, Wu Y, Li J, Bao Y, Guo Y, Yang W. 2018. The Dynamic Changes of Gut Microbiota in Muc2 Deficient Mice. Int J Mol Sci 19:2809.

17. Heazlewood CK, Cook MC, Eri R, Price GR, Tauro SB, Taupin D, Thornton DJ, Png CW, Crockford TL, Cornall RJ, Adams R, Kato M, Nelms KA, Hong NA, Florin THJ, Goodnow CC, McGuckin MA. 2008. Aberrant mucin assembly in mice causes endoplasmic reticulum stress and spontaneous inflammation resembling ulcerative colitis. PLoS Med 5:e54.

18. Liso M, De Santis S, Verna G, Dicarlo M, Calasso M, Santino A, Gigante I, Eri R, Raveenthiraraj S, Sobolewski A, Palmitessa V, Lippolis A, Mastronardi M, Armentano R, Serino G, De Angelis M, Chieppa M. 2020. A Specific Mutation in Muc2 Determines Early Dysbiosis in Colitis-Prone Winnie Mice. Inflamm Bowel Dis 26:546-556.

19. Kumar M, Leon-Coria A, Cornick S, Petri B, Mayengbam S, Jijon HB, Moreau F, Shearer J, Chadee K. 2020. Increased intestinal permeability exacerbates sepsis through reduced hepatic SCD-1 activity and dysregulated iron recycling. Nat Commun 11:483-15.

20. Kissoon-Singh V, Moreau F, Trusevych E, Chadee K. 2013. Entamoeba histolytica exacerbates epithelial tight junction permeability and proinflammatory responses in Muc2(-/-) mice. Am J Pathol 182:852-865.

21. Zarepour M, Bhullar K, Montero M, Ma C, Huang T, Velcich A, Xia L, Vallance BA. 2013. The mucin Muc2 limits pathogen burdens and epithelial barrier dysfunction during Salmonella enterica serovar Typhimurium colitis. Infect Immun 81:3672-3683.

22. Hasnain SZ, Wang H, Ghia J-E, Haq N, Deng Y, Velcich A, Grencis RK, Thornton DJ, Khan WI. 2010. Mucin gene deficiency in mice impairs host resistance to an enteric parasitic infection. Gastroenterology 138:1763-1771.

23. Vázquez-Boland JA, Kuhn M, Berche P, Chakraborty T, Domínguez-Bernal G, Goebel W, González-Zorn B, Wehland J, Kreft J. 2001. Listeria pathogenesis and molecular virulence determinants. Clin Microbiol Rev, 2nd ed. 14:584-640.

24. Pron B, Boumaila C, Jaubert F, Sarnacki S, Monnet JP, Berche P, Gaillard JL. 1998. Comprehensive study of the intestinal stage of listeriosis in a rat ligated ileal loop system. Infect Immun 66:747-755.

25. Lindén SK, Bierne H, Sabet C, Png CW, Florin TH, McGuckin MA, Cossart P. 2008. Listeria monocytogenes internalins bind to the human intestinal mucin MUC2. Arch Microbiol 190:101-104.

26. Coconnier MH, Dlissi E, Robard M, Laboisse CL, Gaillard JL, Servin AL. 1998. Listeria monocytogenes stimulates mucus exocytosis in cultured human polarized mucosecreting intestinal cells through action of listeriolysin O. Infect Immun 66:3673-3681.

27. Liévin-Le Moal V, Huet G, Aubert J-P, Bara J, Forgue-Lafitte M-E, Servin AL, Coconnier M-H. 2002. Activation of mucin exocytosis and upregulation of MUC genes in polarized human 
bioRxiv preprint doi: https://doi.org/10.1101/2020.10.21.348896; this version posted October 21, 2020. The copyright holder for this preprint

(which was not certified by peer review) is the author/funder, who has granted bioRxiv a license to display the preprint in perpetuity. It is made available under aCC-BY-NC-ND 4.0 International license.

intestinal mucin-secreting cells by the thiol-activated exotoxin listeriolysin O. Cell Microbiol $4: 515-529$.

28. Nikitas G, Deschamps C, Disson O, Niault T, Cossart P, Lecuit M. 2011. Transcytosis of Listeria monocytogenes across the intestinal barrier upon specific targeting of goblet cell accessible E-cadherin. J Exp Med 208:2263-2277.

29. Zhang T, Abel S, Abel Zur Wiesch P, Sasabe J, Davis BM, Higgins DE, Waldor MK. 2017. Deciphering the landscape of host barriers to Listeria monocytogenes infection. Proc Natl Acad Sci USA 114:6334-6339.

30. Wollert T, Pasche B, Rochon M, Deppenmeier S, van den Heuvel J, Gruber AD, Heinz DW, Lengeling A, Schubert W-D. 2007. Extending the host range of Listeria monocytogenes by rational protein design. Cell 129:891-902.

31. Chassaing B, Aitken JD, Malleshappa M, Vijay-Kumar M. 2014. Dextran sulfate sodium (DSS)-induced colitis in mice. Curr Protoc Immunol 104:15.25.1-15.25.14.

32. Abel S, Abel Zur Wiesch P, Chang H-H, Davis BM, Lipsitch M, Waldor MK. 2015. Sequence tag-based analysis of microbial population dynamics. Nat Methods 12:223-6- $3 \mathrm{p}$ following 226.

33. Bhardwaj V, Kanagawa O, Swanson PE, Unanue ER. 1998. Chronic Listeria infection in SCID mice: requirements for the carrier state and the dual role of T cells in transferring protection or suppression. J Immunol 160:376-384.

34. Melton-Witt JA, Rafelski SM, Portnoy DA, Bakardjiev AI. 2012. Oral infection with signature-tagged Listeria monocytogenes reveals organ-specific growth and dissemination routes in guinea pigs. Infect Immun 80:720-732.

35. Furter M, Sellin ME, Hansson GC, Hardt W-D. 2019. Mucus Architecture and Near-Surface Swimming Affect Distinct Salmonella Typhimurium Infection Patterns along the Murine Intestinal Tract. Cell Rep 27:2665-2678.e3.

36. McLoughlin K, Schluter J, Rakoff-Nahoum S, Smith AL, Foster KR. 2016. Host Selection of Microbiota via Differential Adhesion. Cell Host Microbe 19:550-559.

37. Cornick S, Kumar M, Moreau F, Gaisano H, Chadee K. 2019. VAMP8-mediated MUC2 mucin exocytosis from colonic goblet cells maintains innate intestinal homeostasis. Nat Commun 10:4306-14.

38. Cornick S, Moreau F, Gaisano HY, Chadee K. 2017. Entamoeba histolytica-Induced Mucin Exocytosis Is Mediated by VAMP8 and Is Critical in Mucosal Innate Host Defense. MBio 8:e01323-17.

39. Mengaud J, Ohayon H, Gounon P, Mege R-M, Cossart P. 1996. E-cadherin is the receptor for internalin, a surface protein required for entry of L. monocytogenes into epithelial cells. Cell 84:923-932. 
bioRxiv preprint doi: https://doi.org/10.1101/2020.10.21.348896; this version posted October 21, 2020. The copyright holder for this preprint

(which was not certified by peer review) is the author/funder, who has granted bioRxiv a license to display the preprint in perpetuity. It is made available under aCC-BY-NC-ND 4.0 International license.

40. Hoffman CL, Lalsiamthara J, Aballay A. 2020. Host Mucin Is Exploited by Pseudomonas aeruginosa To Provide Monosaccharides Required for a Successful Infection. MBio 11:183.

41. Wheeler KM, Cárcamo-Oyarce G, Turner BS, Dellos-Nolan S, Co JY, Lehoux S, Cummings RD, Wozniak DJ, Ribbeck K. 2019. Mucin glycans attenuate the virulence of Pseudomonas aeruginosa in infection. Nat Microbiol 4:2146-2154.

42. Pacheco AR, Curtis MM, Ritchie JM, Munera D, Waldor MK, Moreira CG, Sperandio V. 2012. Fucose sensing regulates bacterial intestinal colonization. Nature 492:113-117.

43. Johansson MEV, Gustafsson JK, Holmén-Larsson J, Jabbar KS, Xia L, Xu H, Ghishan FK, Carvalho FA, Gewirtz AT, Sjövall H, Hansson GC. 2014. Bacteria penetrate the normally impenetrable inner colon mucus layer in both murine colitis models and patients with ulcerative colitis. Gut 63:281-291.

44. Ermund A, Schütte A, Johansson MEV, Gustafsson JK, Hansson GC. 2013. Studies of mucus in mouse stomach, small intestine, and colon. I. Gastrointestinal mucus layers have different properties depending on location as well as over the Peyer's patches. Am J Physiol Gastrointest Liver Physiol 305:G341-7.

45. Johansson MEV. 2012. Fast renewal of the distal colonic mucus layers by the surface goblet cells as measured by in vivo labeling of mucin glycoproteins. PLoS ONE 7:e41009.

46. Morampudi V, Dalwadi U, Bhinder G, Sham HP, Gill SK, Chan J, Bergstrom KSB, Huang T, Ma C, Jacobson K, Gibson DL, Vallance BA. 2016. The goblet cell-derived mediator RELM- $\beta$ drives spontaneous colitis in Muc2-deficient mice by promoting commensal microbial dysbiosis. Mucosal Immunol 9:1218-1233.

47. Davis MPA, van Dongen S, Abreu-Goodger C, Bartonicek N, Enright AJ. 2013. Kraken: a set of tools for quality control and analysis of high-throughput sequence data. Methods 63:41-49.

48. Caporaso JG, Kuczynski J, Stombaugh J, Bittinger K, Bushman FD, Costello EK, Fierer N, Peña AG, Goodrich JK, Gordon JI, Huttley GA, Kelley ST, Knights D, Koenig JE, Ley RE, Lozupone CA, McDonald D, Muegge BD, Pirrung M, Reeder J, Sevinsky JR, Turnbaugh PJ, Walters WA, Widmann J, Yatsunenko T, Zaneveld J, Knight R. 2010. QIIME allows analysis of high-throughput community sequencing data. Nat Methods 7:335-336.

49. Cavalli-Sforza LL, Edwards AW. 1967. Phylogenetic analysis. Models and estimation procedures. Am J Hum Genet 19:233-257. 
Figure 1

a

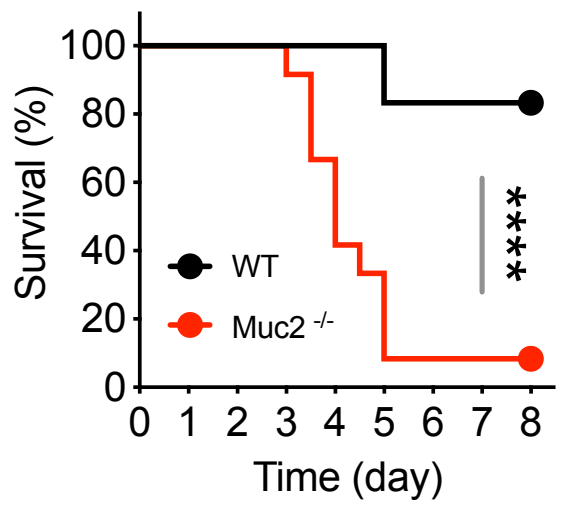

b

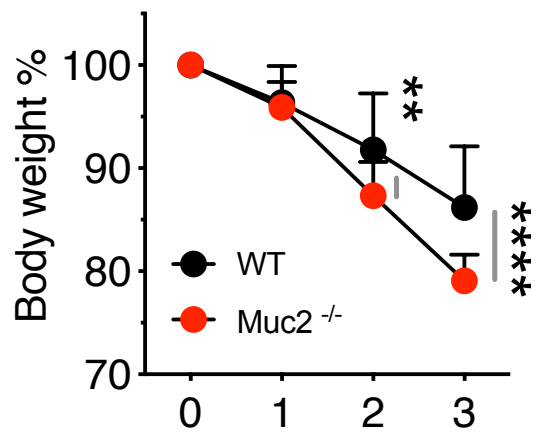

Days post infection 
Figure 2
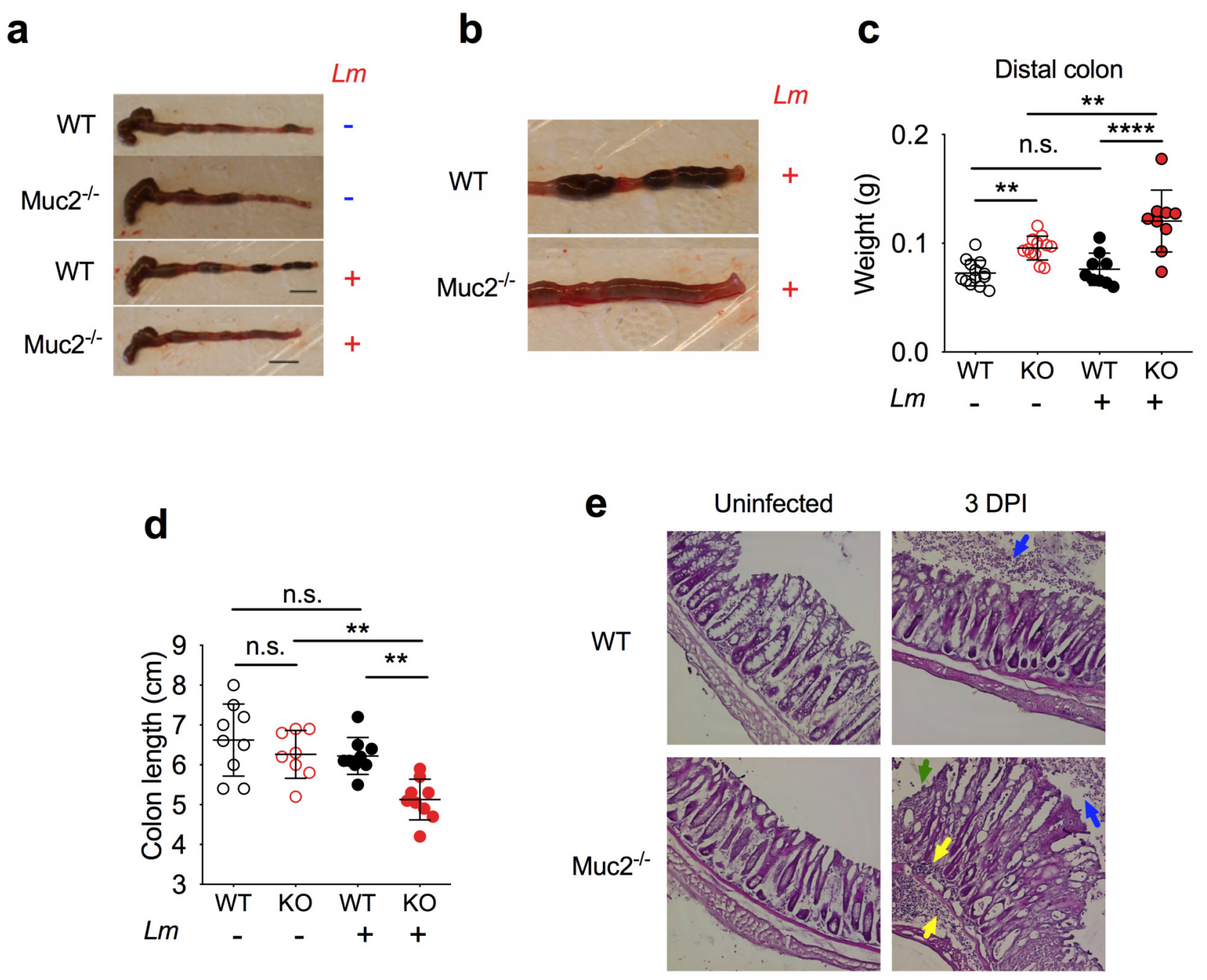
Figure 3

a

Small intestine

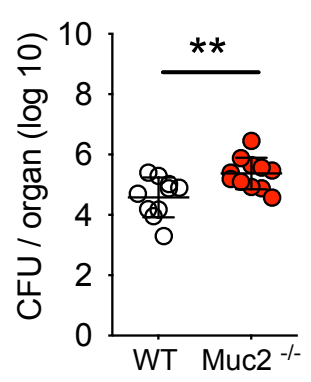

b

Proximal colon

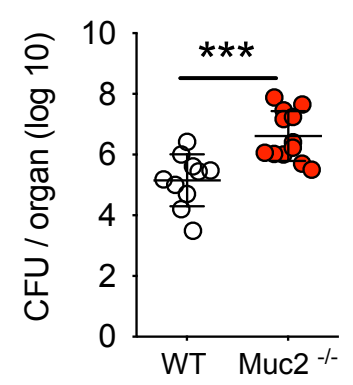

C

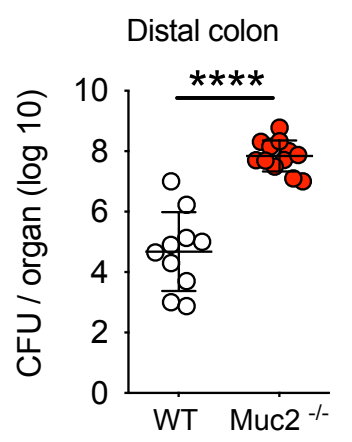

d

MLN

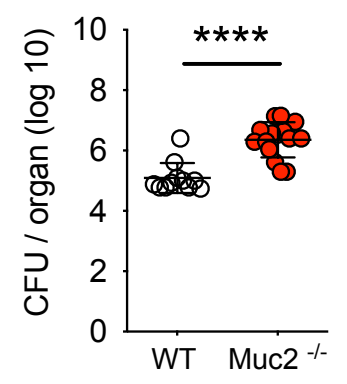

e

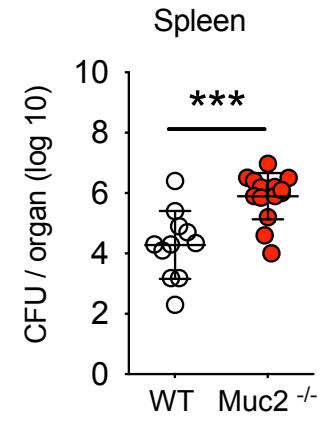

f

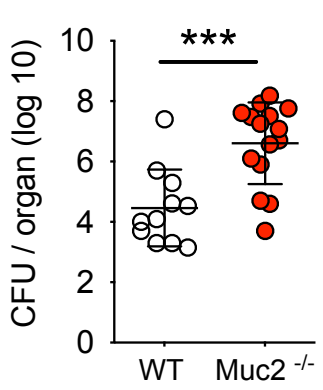

g

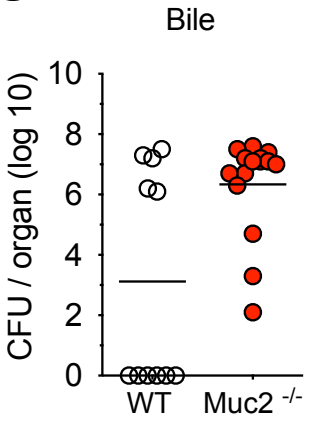


Figure 4
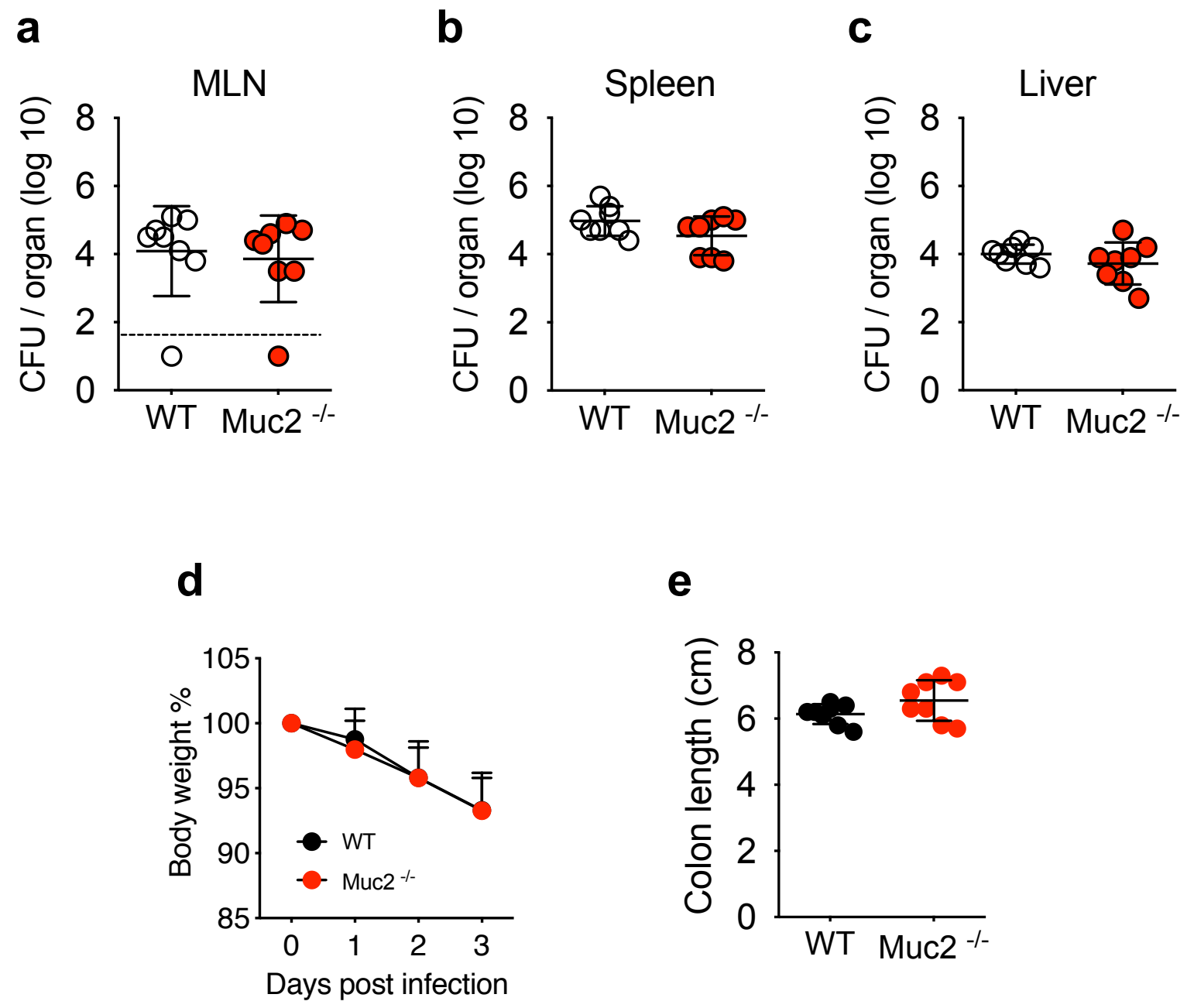

e

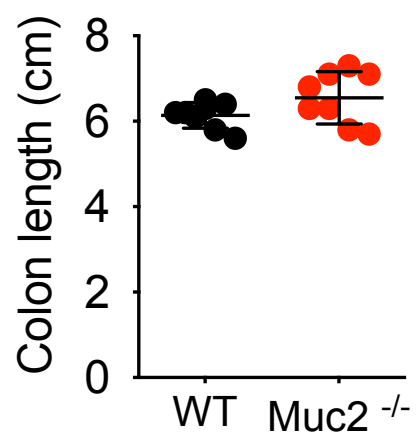


Figure 5
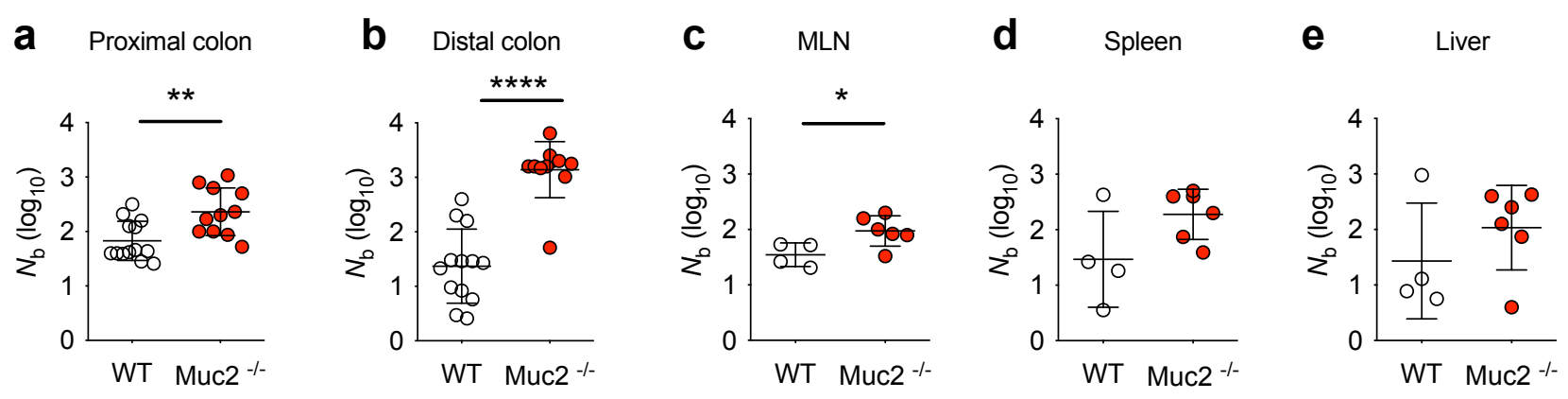

f proximal colon / MLN

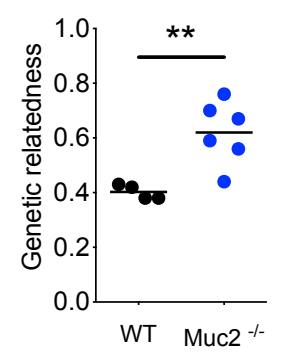

g proximal colon / spleen

h proximal colon / liver
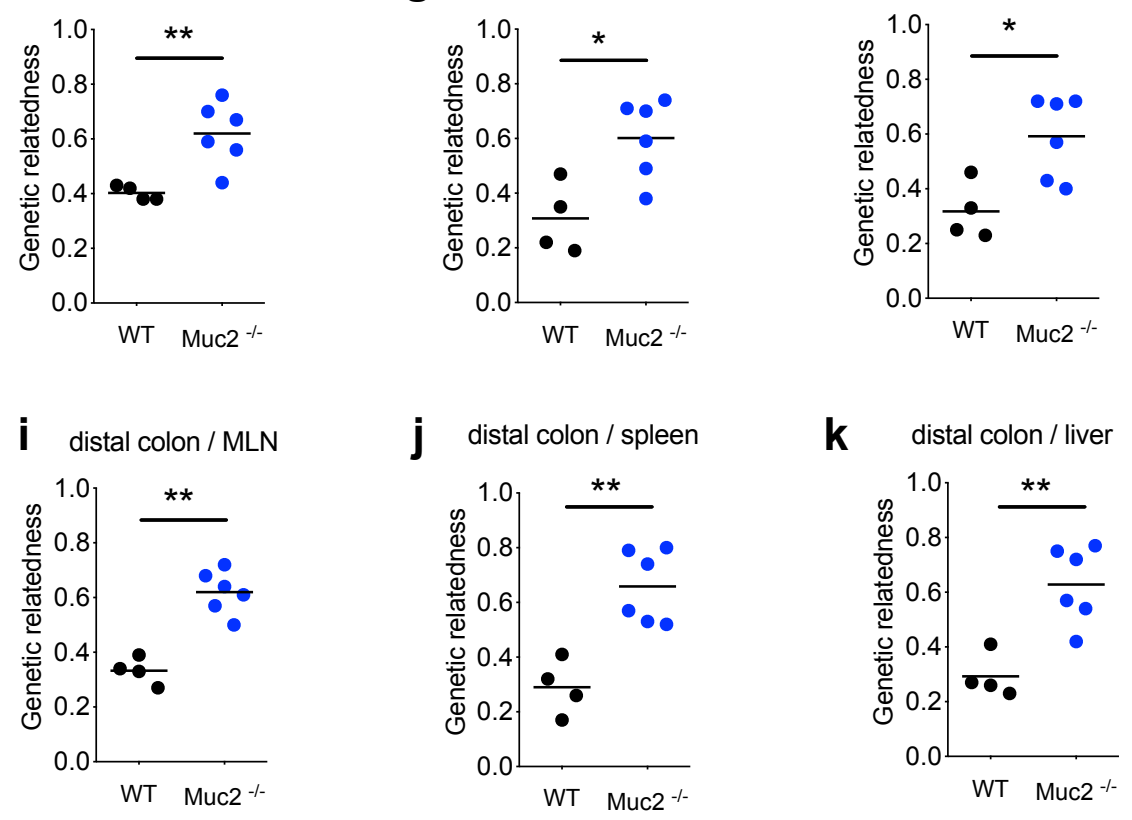
bioRxiv preprint doi: https://doi.org/10.1101/2020.10.21.348896; this version posted October 21, 2020. The copyright holder for this preprint (which was not certified by peer review) is the author/funder, who has granted bioRxiv a license to display the preprint in perpetuity. It is made available under aCC-BY-NC-ND 4.0 International license.

Figure S1

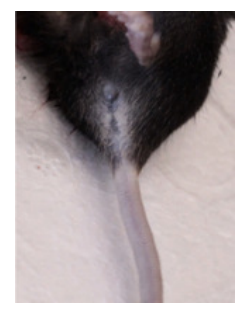

WT

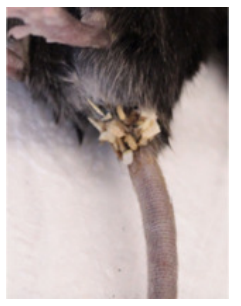

Muc2 ${ }^{-1-}$

Figure S2

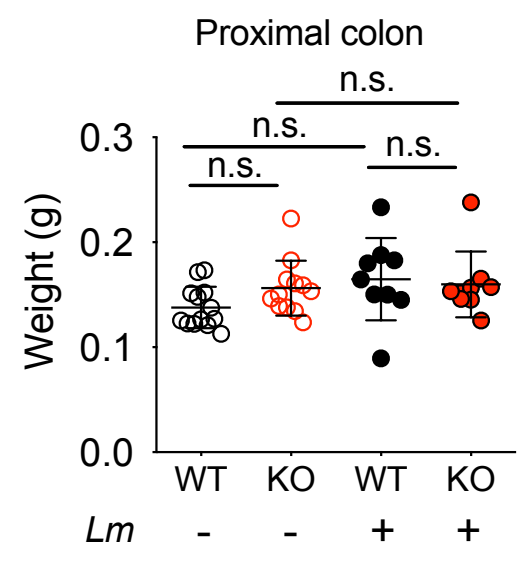

Figure S3

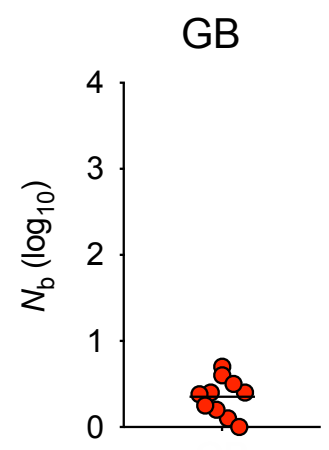

Muc2 ${ }^{-1}$ 